"On the causes which produce the phenomena of new stars," an historical summary of various theories is given.

The Companions of Procyon and Sirivs.-Prof. Kreutz, telegraphing from Kiel on Sunday, has informed us that Prof. Schaeberle, of the Lick Observatory, has discovered a companion to Procyon. Its position angle was measured as $3 \mathrm{I}^{\circ}$, the distance being $4^{\prime \prime} \cdot 6$; its magnitude is 13 .

A communication from Prof. Holden tells us that Clark's companion to Sirius has been also observed at the Lick by Prof: Aitken on October 24 (position angle $189^{\circ} \circ$, distance $3^{\prime \prime} \cdot 81$ ), October 29, and October 31 , and by Prof. Schaeberle on October 29 and 31 (position angle $189^{\circ} \cdot I$ and clistance $3^{\prime \prime} \cdot 65$ ). Nothing was seen of the companion at position-angle $220^{\circ}$, as reported by Dr. See.

"Brisbane Astronomical Society."-Under this title a new astronomical society has just been founded ; the formation being in this wise. A 6 -inch refractor, equatorially mounted, belonging to Mr. F. D. G. Stanley, Toowong, was for sale. To keep the instrument in the colony Mr. Dudley Eglinton prepared a short subscription list, and obtained sufficient contributions to purchase it. Seventy subscribers of $£ \mathrm{r}$ were obtained, and their

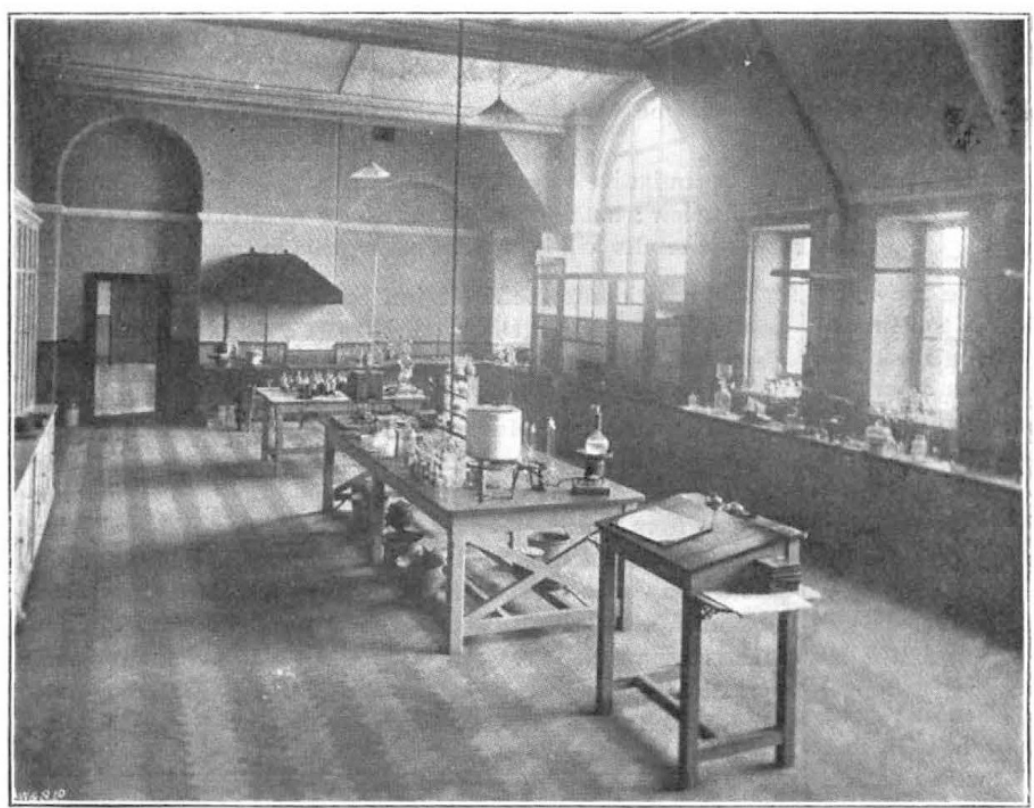

FIG. I.

subscriptions were sufficient to secure the telescope, the observatory, and "all that therein is." The purchasers then formed themselves into an astronomical society. Arrangements have been made for different sections of the society to carry out distinct branches of work, and certain evenings have been fixed when members can use the telescope. We look forward to results from this co-operative astronomical observatory.

"Bulletin de la Sociétí. Astronomioue de France." The November number of this journal contains three beautiful reproductions of the enlargements made by Prof. Weineck from the Lick photographs of the lunar surface. The first of these shows the crater $T y c h o$ and the mountainous region around it, the scale of enlargement from the original negative being about eleven times; this photograph was taken last year in October, that is about two days before the moon's last quarter. The second shows the smaller craters around Flammarion, while the third gives one a grood view of that enormous crater Clavius, which has a diameter of 230 kilometres, or nearly three times that of Tycho. M. Gilbert gives a first contribution on mechanical proofs of the earth's rotation, dealing chiefly, in this number, with the different experiments carried out of dropping bodies from aigh elevations, and from the top of deep pits. An observer, stationed at Li-ka-wei in China, gives a brief description of the eclipse of the sun of August 9, which was unfortunately only NO. I 4 I 2, VOL. 55] partial there. He relates that the atmospheric conditions were excellent, which were more than they were on the island at Yéso, as our observers can testify. Photographs were taken at the most interesting stages of the phenomenon.

\section{THE WORK OF THE SCIENTIFIC AND TECHNICAL DEPARTMENT OF THE IMPERIAL INSTITUTE.}

THE Scientific and Technical Department of the Imperial Institute has been recently inaugurated in order to provide for the scientific investigation of Indian and Colonial natural products, especially those which are new or little known, chiefly with a view to their utilisation in commerce, in medicine, and the arts, both within the British Empire itself, and also in foreign countries. The capacious rooms on the west corridor of the second floor have now been equipped as laboratories (Figs. I and 2), instrument rooms, and sample preparation rooms, to which a small reference library has been added; and a staff of skilled chemists has been appointed to assist in investigating problems relating to the utilisation of natural products of all kinds which have been referred to the Department by the Government of India, or by the Colonial Governments.

The necessary funds for the appointment: of a skilled staff aclequate for the commencement of operations have been contributed, with far-sighted generosity, by H.M. Commissioners of the 185I Exhibition, who make an annual grant for the purpose ; whilst the Goldsmiths' Company have made themselves responsible for the provision of the whole of the equipment of the laboratories and much of the special apparatus required. Besides this, grants are made by the Government of India towards the expenses of prosecuting Indian inquinies whilst the Executive Council of the Imperial Institute, in addition to setting aside an annual sum from its general fund, on which there are already numerous and heavy calls (including the enormous sum of $5000 \%$. per annum, for Government and parochial rates and taxes), undertakes to defray expenses of a general character, both in respect of equipment and maintenance. The Im. perial Government at present renders no pecuniary assistance, either directly or indirectly, to the Department. Gifts of physical and chemical instruments have been made by Dr. Ludwig Mond, F.R.S., and by Mr. George Matthey, F.R.S. The Salters' Company have rendered signal assistance io the undertaking, by founding, in association with the Department, a Research Fellowship of the value of $\delta_{150}$, it being understood that the Salters' Company's Research Fellow shall primarily devote himself to inquiries into the chemistry of medicinal plants of Indian and Colonial origin. In another direction, too, the Salters' Company have assisted the work of the Scientific Department by endowing at St. Thomas's Hospital an additional Research Fellowship, the holder of which is expected to devote himself to inquiries into the action of drugs; so that in this way the medicinal action and remedial value of Indian and Colonial drugs, which are being chemically investigated in the Scientific Department, may be made the subject of medical study by the Salters' Research Fellow in Pharmacology at St. Thomas's Hospital. There is so much important work to be done in determining the medicinal value and precise mode of action of both old and new drugs and their constituents, that the need is already felt of further assistance in this direction.

Provision of the same kind will also be needed for conducting paral'el inquiries:in economic botany, particularly in the direc-

1 Abst act of a ecture delivered at the Imperial Institute on Novemb $\mathrm{r}$ 9, by Frof. Wyndham R. Dunstan, F.R.S., Sec. C.' S., Director of the Scientific Department Sir Joseph Lister, Bart.. President of the Royal Society, in the chair. 
tion of the anatomical study and identification of economic products of vegetable origin.

It may therefore be said that there now exists, in connection with the Imperial Institute, the framework of the necessary machinery for making scientific and technical investigations of natural products of every description from all parts of the Empire. But however numerous the staff of the Department may in the future become, it is unlikely that it will ever be able to cope successfully with the enormous mass of material which present experience shows is likely to be laid before it for investigation.

There has already been formed in connection with the Department an external staff of honorary scientific and technical referees, who are high authorities on their special subjects, and who have undertaken to advise the Department on any questions which may be referred to them. The Department has been also fortenate in securing the co-operation and advice of members of the staffs of several of the most eminent public institutions in this country, and particularly of those which are furnished with appliances for undertaking special technical inquiries. Among these may be mentioned the Royal College of Science and the City Guilds Central Technical College, both of which are adjacent to the Imperial Institute at South Kensington, St. Thomas's Hospital, the Pharmaceutical Society, the Royal Indian Engineering College at Cooper's Hill, the Government Laboratories at Somerset House, at the Royal Arsenal, Woolwich, and at the Royal Mini, also the Yorkshire College at Leeds, where much valuable assistance has been rendered by the Research Laboratory of the Dyeing Department, which is endowed and maintained by the Clothworkers' Company. It is hoped that it may be possible greatly to extend this system of external referees on scientific and technical matters, and to secure the co-operation and assistance of the leading scientific and technical institutions, not only in this country but also in India and the Colonies. For while there can be no doubt that it is advan. tageous that the scientific examination and commercial valuation of Indian and Colonial natural products should in most cases be conducted in the metropolis, still much of the preliminary as well as some of the later operations in connection with, and arising out of these inquiries, might often be conducted in the university and technical laboratories and in the botanical gardens of our Colonies, especially if their instructions were federated with, and were working in association with the Central Scientific and Technical Department at the Im-

perial Institute. Such a federation, through the Imperial Institute, of scientific and technical workers in all parts of the Empire, could not fail to be an important source of strength to science, industry, and to the nation at large.

The principal work which the new department of the Imperial Institute is prepared to undertake when requested by the Indian or Colonial Governments, may be summarised as follows :-

(I) The scientific investigation of new or little-known natural products derived from India and the Colonies, with a view to their commercial utilisation throughout the Empire.

(2) The comparative examination with the same ends in view, of products of recognised value and importance, which, although known to occur and to be producible in India and the Colonies, are at present obtained commercially from other sources.

(3) Advising the Indian and Colonial Governments on all scientific questions relating to the production, manufacture, and commercial utilisation of materials occurring within the British Empire.

In order that the new organisation may be of real utility to India and the Colonies, it is necessary that their Governments, through their recognised representatives in this country, should bring themselves into close communication with the scientific department, and be the means of transmitting inquiries and suggestions from their respective Dominions as to the investiga- tions which should be made, and also reporing to their respective Governments the result of the inquiries and the recommendations based upon them.

It may be useful to allude here to the excellent preliminary arrangements which have already been made by the Indian Government for this purpose ; for the example thus set by India will, it is hoped, be followed by at least all the more important of our colonies. The Government of India has arranged that information as to the questions demanding attention shall be obtained in Calcutta by a specially appointed officer attached to the Revenue and Agricultural Department, the Reporter on Economic Products, Dr. George Watt, C.I.E., who is in constant communication, through the India Office, with the Imperial Institute, and is charged with the collection, in India, of samples of the various products requiring investigation, and their transmission to the Imperial Institute, together with suggestions as to the points needing inquiry.

The arrangements connected with the disposal of these pro ducts are made by a special Committee appointed by the Secre tary of State for India, which is presided over by Sir Steuart Bayley, K.C.S.I., and consists of Indian officials who are familiar with the needs of India, and the possibilities of

$$
\text { NO. } 14 \text { I } 2 \text {, VOL. 55] }
$$

promoting Indian commerce, viz. :-Sir Charles Bernard, K.C.S.I., Sir Owen Tudor Burne, K.C.S.I., Sir George Birdwood, M.D., K.C.S.I., and Sir Alexander Wilson, K.C.S.I. The experienced Curator of the Indian Section of the Imperial Institute, Mr. J. R. Royle, C.I.E., acts as secretary. To this Committee is added any official of the Government of India who may be on leave in this country, and is likely to be able to render assistance.

The Committee is charged with the maintenance and renewal of a thoroughly representative collection in the galleries of the Imperial Institute, illustrative of the chief natural products and principal manufactures of India. A similar but more extensive collection is maintained, under the supervision of Dr. Watt, at the Indian Museum at Calcutta.

The Committee receives periodical reports from the Director of the Scientific Department of the progress of investigations, and acts as the channel of transmission to India of results and recommendations.

Now that the Scientific and Technical Research Department has been organised on its experimental side, the Executive Council of the Imperial Institute have in view the perfection of preliminary arrangements that have already been made to bring the results and information obtained by this department under the immediate notice of merchants and others who control 
British and foreign markets, and in this matter, too, they will look for active assistance and co-operation from all the Colonies.

No account of the organisation of the Scientific and Technical Research Department would be complete without some reference to the part which Sir Frederick Abel, the Secretary and Director of the Institute, has played in this matter. The bringing into existence and into prominence of this side of the work of the Imperial Institute, the importance of which was fully realised by its founders, is mainly due to his enthusiasm and energy, and indomitable courage in face of numerous difficulties.

The following is a brief epitome of the more important work which is at the present time occupying the attention of the Department.

The Indian Coal Supply.-Chemical analyses are being made in order to determine the value of the coal deposits occurring in different parts of India, and the results thus obtained are being supplemented by practical tests.

The Iron Ores of India.-Chemical examinations are being made of the deposits of iron ore occurring in different districts of India, and after the analytical results have been obtained the question of the best methods of smelting these ores will be investigated. The examination of a number of specimens derived from the Salem district of Madras, and composed generally of magnetite, has already been completed.

Indian and Colonial Fibres. - The chemical examination is being conducted, and practical tests are being made of the chief Indian and Colonial fibres, with a view to the cultivation of those which prove to be of commercial value. A chemical investigation is also being made of the composition of jute fibre at different stages of its growth, with the view of determining the influence of age on the composition and strength of jute fibre cultivated in India. Special experiments are in progress in reference to the possibility of chemical treatment of jute fibre in India, with a view of retarding or preventing certain changes which occur during its transport to this or other countries. In their inquiries the Department has the advantage of the advice of Mr. G. F. Cross and Mr. C. E. Collyer.

Indian Opium.-A systematic inquiry is being conducted into the methods used in the production of opium in India, with a view to improving the quality of Indian opium for medical use and for the manufacture of morphia and other valuable alkaloids. In connection with this inquiry the Government of India is causing to be collected a number of specimens of poppies, of opium, and of the bye-products and materials used in preparing it in each of the opium districts of India.

Indian and Colonial Medicinal Plants. - The chemical examination and therapeutic trial of the constituents of a number of important Indian and Colonial medicinal plants is in progress, with the object of determining which are of real medical value, and a similar examination is being made of certain well-known drugs which it would appear might be successfully cultivated in India and the Colonies.

Essential Oils and Perfumes.-A preliminary chemical examination of a number of essential oils and perfumes produced at the Government Flower Farm at Dunolly in Victoria has been completed, by M. Umney, and these are also being compared, with especial reference to their commercial value, with the best English and French oils now in commerce.

Indian Dye-stuffs. - The chemical examination of the principal Indian dye-stuffs has been undertaken in order to ascertain the nature of the chief colouring matters, and to determine which are likely to be valuable as dyes, and to ascertain the best methods or employing them. Most of this work is being carried on by Prof. Hummel and Mr. A. G. Perkins in the Clothworkers Research Laboratory at the Yorkshire College, Leeds.

The Food Grains of India.-A systematic investigation of the constituents of Indian food grains is being conducted, their chief constituents are being ascertained, and their dietetic value determined. This inquiry includes not merely new grains, but also the effect which climate, altitude and other conditions may have upon various well-known grains which are grown in India. On these subjects the Department has secured the valuable assistance of Prof. B. H. Church, F.R.S., and of Mr. Horace Brown, F.R.S

Indian and Colonial Tanning Materials.-A number of Indian and Colonial plants which have been proved to possess, or are likely to have, value as tanning materials, is being conducted, and information is being obtained as to the best methods of cultivating them, and the most suitable time of collecting them for use as tanning agents.
Indian and Colonial Timbers. - A large number of Indian and Colonial timbers, specially selected by the Governments, have been submitted to mechanical tests and practical trial, so that their commercial value might be accurately determined. This work has been conducted by Prof. W. C. Unwin, F.R.S., at the Central Technical College.

All that has been attempted in this lecture is to afford a general idea of the character of the principal work on which the Scientific Department is engaged, and of its commercial bearings. The technical results of the inquiries, when complete, will be communicated to the Colonies and afterwards published, whilst any results of strictly scientific interest which may be gained will be communicated to the appropriate Scientific Society. The results of many of the inquiries must necessarily be almost entirely of technical interest, but in some cases problems of considerable scientific interest are raised. The dividing line between science and practice is hard to draw in investigations of this kind, and the interests at stake will not be faithfully served if scientific, as well as immediately practical ends, are not kept in view. It often happens that the science of to-day becomes the practice of to-morrow.

From what has been said to-night, it will be evident that the operations of the Imperial Institute in its Scientific and Technical Department are such as to command sympathy and active support in this country, as well as in India and the Colonies. It is to be hoped that all possible assistance may be rendered in ex tending the sphere of influence of this Department, so that it ultimately may become an Imperial Bureau of Scientific and Technical Advice, having for its chief object the acquisition of exact knowledge of the natural resources of this great empire.

\section{EXPERIMENTS ON RÖNTGEN RAYS.}

The Introduction of the use of the Camera to reduce the Size of Plates.

WE have yet no means of bringing Röntgen rays to a focus but the thought occurred to me that instead of using large plates to cover half of the body, one might photograph the shadows as seen on the fluorescent screen by means of the camera. It was evident uniformity and steadiness of illumination for a period would be necessary ; these were obtained by the methods adopted under the next heading. I tried this experiment by simply placing the camera and lens in front of the fluorescent screen and focusing on the ordinary ground glass. This experiment gave a much-reduced picture in an exposure of I minute 50 seconds, but a very curious result was also cbtained. Clearly enough I got a photograph of the screen with the pair of forceps on it reduced in the proportion of 12 to 2 in size, but all the X-rays had not been stopped by the potassium platinocyanide screen, and although the camera was four feet from the tube, a sufficient number of rays had passed through the screen to give me a picture (on the same plate) of the brass mountings and lens of the camera. On the sensitive plate, therefore I had obtained two pictures, one due to the ordinary rays of light from the fluorescent screen, and the other due to Rontgen rays. In the former the object was reduced, the ordinary rays having been focused by the lens, and in the latter the shadow of the brass mountings and lens of the camera were enlarged owing to the divergence of the Röntgen rays. In my next attempt I covered the front of the camera with a sheet of lead, in which I had cut a hole sufficient to allow the lens to pass through. The lens prevented the Röntgen rays going through the centre, and the lead on the outside protected the remainder of the plate, so that only one picture was got, showing a reduced photograph of the hand with the bones of the fingers quite well defined. By this means I hope to reduce the time of exposure. Now, by this new method we may be able to reduce a picture of a large portion of the human body to magic-lantern slide size right away. Another thing was noticed in this experiment-the barium salt did not photograph as easily as the potassium; but it must be remembered that the barium is yellowish-green in colour, while the potassium is blue or even slightly violet.

Another important point to be gathered from the above experiments may be noted. While we have been striving to produce more Röntgen rays in the tube, it is evident we are not utilising what we have with our present fluorescent screens. I placed three ordinary screens in front of each other, one foot apart, and found that while each became luminous under the infuence of Röntgen rays, a sufficient number of them were still

NO. I 4 I 2 , VOL. 55$]$ 